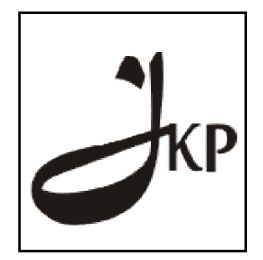

Jurnal Konseling dan Pendidikan

ISSN Cetak: 2337-6740 - ISSN Online: 2337-6880

http://jurnal.konselingindonesia.com

Volume 3 Nomor 3, November 2015, HIm 56-61

Info Artikel:

Diterima 16/10/2015

Direvisi 18/11/2015

Dipublikasikan 28/11/2015

\title{
PEMAHAMAN KONSEP PERUBAHAN DAN KEGUNAAN BENDA DENGAN METODE SMART GAME\& PEMBELAJARAN KOOPERATIF TIPE MAKE $A$ MATCH DALAM MATA PELAJARAN IPA DI SDN 12 NAN SABARIS
}

Suatri

Abstract

Results of preliminary observations at several elementary schools shows that there are some constraints faced by teachers in the learning process. One problem is difficult to cultivate an understanding of the concept of identifying objects are known and their usefulness to students through observation. The purpose of this action research are (1) to determine that the method of smart games and cooperative learning make a match can improve the understanding of the concept of identifying objects are known and their use through observation, (2) to improve the students' tasks in groups in understand the concept of identifying objects are known and their use through observation. Data obtained through tests and usage observation guide, the data is processed by a percentage. Results of the analysis of the data obtained in the first cycle of learning success; $64.00 \%$, and the second cycle; amounting to $83.50 \%$. So the smart methods of cooperative learning the game and make a match indicates no increase student learning from the first cycle to the second cycle. Thus the smart methods of cooperative learning the game and make a match can improve the understanding of the concept of identifying objects are known and their use through observation of students. The cooperation of students in completing the task in groups also increased, proved more active play looking for a partner in the group and the ability to group tasks more quickly and perfectly.

Keyword: comprehension of concepts, objects change shape and utility objects.

Copyright (C) 2015 IICET (Padang - Indonesia) - All Rights Reserved

Indonesian Institute for Counseling, Education and Theraphy (IICET)

\section{PENDAHULUAN}

Berdasarkan observasi pendahuluan pada beberapa sekolah di kecamatn Nan Sabaris, seperti SDN 12 Nan Sabaris, terdapat beberapa kendala yang dihadapi guru dalam pembelajaran IPA. Salah satu kendalanya adalah dalam mengajarkan konsep mengidentifikasi benda-benda yang dikenal dan kegunaannya melalui pengamatan. Menurut para guru, penamaman konsep mengidentifikasi benda-benda yang dikenal dan kegunaannya melalui pengamatan pada siswa sangat sulit. Kesulitan ini disebabkan sulitnya siswa menyebutkan benda-benda yang dikenal dan kegunaannya melalui pengamatan, referensi yang kurang, waktu terbatas, danmetode yang kurangtepatsertatempat yang kurangmemadai.

Dari hasil wawancara dengan para guru SDN 12 Nan Sabaris juga diperoleh keterangan bahwa metodesmart game\&pembelajaran kooperatif tipe make a match belum pernah digunakan dalam proses pembelajaran, khususnya mengidentifikasi benda-benda yang dikenal dan kegunaannya melalui pengamatan. Temuan ini sesuai dengan pendapat Arief (1996) bahwa dalam proses belajar mengajar IPA, guru masih dominan untuk memindahkan ilmu pengetahuan kepada siswa tanpa membuat siswa aktif dalam belajar. Pada kenyataannya, guru lebih banyak menggunakan metode ceramah dalam pembelajaran IPA. Menurut Sukmadinata (1988), guru yang baik adalah guru yang berhasil dalam pengajaran, yaitu guru yang dapat mempersiapkan siswa untuk mencapai tujuan pembelajaran sesuai dengan yang dirumuskan dalam kurikulum. Sudah banyak tulisan yang menyoroti tentang metode smart game\&pembelajaran kooperatif tipe make a match, tetapi penelitianpenelitian tersebut belum menyentuh langsung tentang upaya peningkatan pemahaman konsep khususnya mengidentifikasi benda-benda yang dikenal dan kegunaannya melalui pengamatan.

Proses pembelajaran dengan metode ceramah dalam mata pelajaran IPA cenderung membuat siswa menjadi pasif dan tidak ada keinginan siswa untuk mencoba melakukan penelitian sederhana dalam belajar. Dengan demikian, mempelajari IPA khususnya mengidentifikasi benda-benda yang dikenal dan kegunaannya 
melalui pengamatan diperlukan proses pembelajaran dengan menggunakan pendekatan keterampilan proses. Pendekatan keterampilan proses melatih siswa untuk melakukan pengamatan dan mencoba mencari tahu masalah yang diamati dalam proses pembelajaran.

Pada sisi lain, perolehanhasilbelajarsiswa juga terlihat bahwa rata-rata NEM IPA kelas IIpada SDN 12 Nan Sabaris masih rendah, seperti tahun 2012/2013 sebesar 5,18, 2013/2014 sebesar 4,81. Dan tahun berikutnya 4,47. Lebih rendah dibandingkan mata pelajaran lain, seperti Matematika $(6,26)$, PPKn $(7,16)$, Bahasa Indonesia $(6,76)$, IPS $(6,47)$.

Menyimak gejala-gejala tersebut di atas, diperlukan peningkatan pemahaman konsep mengidentifikasi benda-benda yang dikenal dan kegunaannya melalui pengamatan pada siswa, dan pelaksanaannya dalam pembelajaran dengan menggunakan metodesmart game\&pembelajaran kooperatif tipe make a match sebagai metode mengajar. Metodesmart game\&pembelajaran kooperatif tipe make a matchmerupakan metode dalam bentuk permainan kreatif dan edukatif untuk anak.

Karakteristik permainan (games) adalah untuk menciptakan suasana belajar yang menyenangkan (fun) serta serius tapi santai (dapat disingkat sersan). Permainan digunakan untuk penciptaan suasana yang semula pasif menjadi aktif, kaku menjadi luwes, jenuh menjadi riang (segar). Metode ini diarahkan agar tujuan belajar dapat dicapai secara efektif dan efisien dalam suasana gembira meskipun membahas hal-hal yang sulit.

Tentu saja permainan dalam pembelajaran tidak hanya sekedar permainan atau hanya untuk mengisi kekosongan waktu. Permainan sebaiknya dijadikan sebagai bagian dari proses belajar. Permainan dirancang menjadi suatu aksi / kejadian yang dialami sendiri oleh siswa kemudian dalam proses refleksi, disimpulkan untuk mendapat hikmah yang mendalam. Inilah yang dimaksud dengan metode smart game. Smart berarti cerdas dan game berarti permainan. Smart game adalah permainan yang dirancang sedemikian rupa untuk meningkatkan kecerdasan anak didik.

Dari latar belakang dan landasan teori di atas, masalah dalam penelitian dirumuskan sebagai berikut : (1) Apakah dengan metodesmart game\&pembelajaran kooperatif tipe make a match dengan penerapan model tematik ini dapat meningkatkan prestasi siswa di kelas II Sekolah Dasar Negeri 12 Nan Sabaris ? (2) Apakah metodesmart game\&pembelajaran kooperatif tipe make a match dengan penerapan model pembelajaran tematik ini dapat meningkatkan kemampuan siswa untuk menyerap konsep pembelajaran tematik dalam pelajaran IPA siswa kelas II di Sekolah Dasar Negeri 12 Nan Sabaris ? (3) Apakah melalui metodesmart game\&pembelajaran kooperatif tipe make a match dengan penerapan model pembelajaran tematik dapat menumbuhkan motivasi anak siswa kelas II di Sekolah Dasar Negeri 12 Nan Sabaris ?

Berdasarkanlatar belakang dan rumusan masalah tersebut, maka tujuan penelitian ini adalah (1) Untuk meningkatkan aktifitas belajar siswa dalam pembelajaran IPA melalui metodesmart game\&pembelajaran kooperatif tipe make a match dengan penerapan pembelajaran tematik terhadap siswa (2) Untuk mengetahui efektifitas metodesmart game\&pembelajaran kooperatif tipe make a match dengan penerapan model pembelajaran tematik dalam meningkatkan kemampuan siswa dalam pembelajaran IPA aspek mengidentifikasi benda-benda yang dikenal dan kegunaannya melalui pengamatan bagi siswa (3) Meningkatkan prestasi belajar siswa dalam pembelajaran IPA mengidentifikasi benda-benda yang dikenal dan kegunaannya melalui pengamatan dengan metode smart game\&pembelajaran kooperatif tipe make a match dengan penerapan model pembelajaran tematik kelas II di Sekolah Dasar Negeri 12 Nan Sabaris.

\section{METODE PENELITIAN}

Berdasarkan rumusan masalah dan tujuan penelitian, jenis penelitian ini berbentuk Penelitian Tindakan Kelas (PTK). Menurut Kunandar (2012: 44-45), PTK dapat didefinisikan sebagai :

"Suatu penelitian tindakan (action research) yang dilakukan oleh guru yang sekaligus sebagai peneliti di kelasnya atau bersama-sama dengan orang lain (kolaborasi) dengan jalan merancang, melaksanakan dan merefleksikan tindakan secara kolaboratif dan partisipatif yang bertujuan untuk memperbaiki atau meningkatkan mutu (kualitas) proses pembelajaran di kelasnya melalui suatu tindakan (treatment) tertentu dalam suatu siklus".

Penelitian tindakan dilakukan dalam bentuk siklus (daur ulang). Penelitian dilakukan melalui empat langkah dalam setiap siklus penelitian, yaitu perencanaan (plan), tindakan (action), pengamatan (observation), dan refleksi (reflection). Penelitian direncanakan dalam dua siklus, siklus kedua dilakukan mengacu pada siklus pertama, seperti alur berikut ini. 


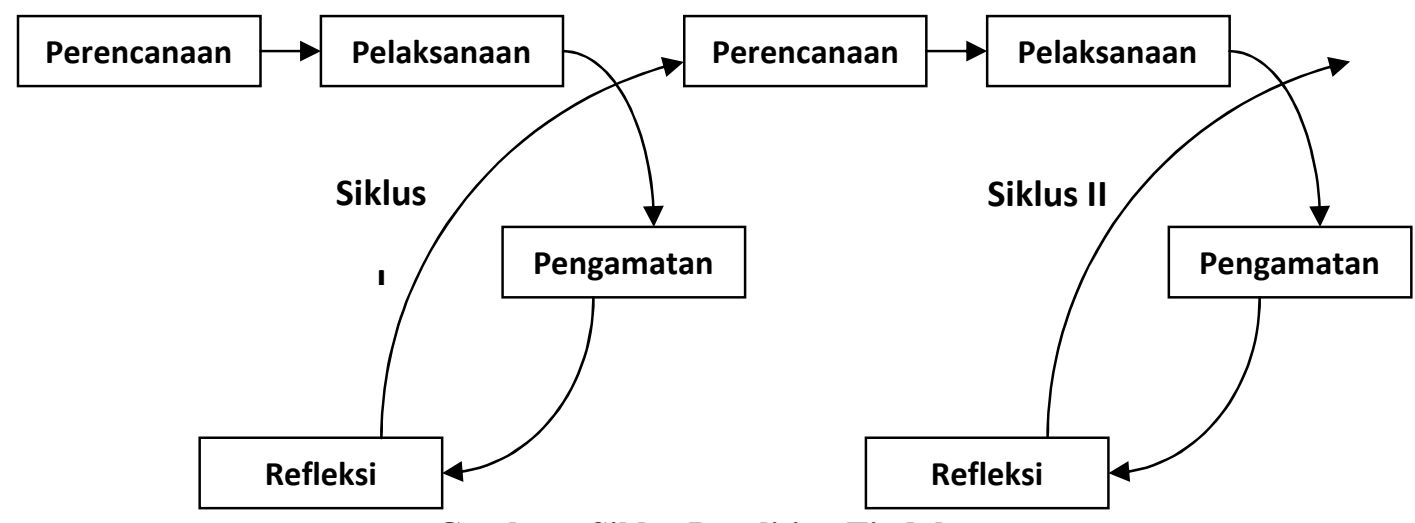

Gambar : Siklus Penelitian Tindakan

Lewin (dalam Kemmins dan McTaggart, 1988) mendeskripsikan penelitian tindakan kelas sebagai tindakan berkelanjutan dari langkah-langkah berbentuk spiral, setiap langkah (siklus) berisi perencanaan, pelaksanaan tindakan, observasi (evaluasi), dan refleksi tindakan. Penelitian ini dilakukan secara kolaborasi antara peneliti dengan kelas II SDN12 Nan Sabaris. Penelitian ini berlangsung 2 siklus, setiap siklus terdiri atas 4 tahap, yaitu (1) tahap perencanaan, meliputi : pembekalan kepada guru, penyusunan model pembelajaran, penyiapan instrumen tes (pretes, postes), lembar observasi dan membentuk kelompok belajar siswa, (2) tahap pelaksanaan tindakan, meliputi: pelaksanaan kegiatan dari perencanaan yang dibuat, (3) tahap observasi, yaitu pengamatan dari pelaksanaan tindakan melalui pedoman observasi, dan (4) tahap refleksi, yaitu menganalisis dan memberi pemaknaan dari pelaksanaan tindakan, sehingga dapat dibuat perencanaan tindakan pada siklus berikutnya.

Data yang telah terkumpul dianalisis dengan rumus persentase. Selanjutnya, nilai yang diperoleh siswa dicocokkan ke dalam tabel konversi nilai dengan skala 5. Hasil analisis ini digunakan untuk mencari ketuntasan belajar. Menurut Depdikbud (1994) ketuntasan belajar secara klasikal sebesar 85\%, dari siswa memperoleh nilai 75 atau $75 \%$, artinya siswa baru dapat dikatakan tuntas belajar bila siswa telah mendapat nilai minimal 75 . Bila siswa memperoleh nilai kurang dari 75 dianggap belum tuntas belajar, selanjutnya bagi siswa yang bersangkutan dimasukkan ke dalam 1 atau 2 kelompok tergantung dari jumlah siswa yang belum tuntas belajar. Siswa inilah yang mendapatkan perhatian (fokus) dari guru saat pelaksanaan tindakan pada siklus-siklus berikutnya.

\section{HASIL PENELITIAN DAN PEMBAHASAN \\ Hasil Belajar}

Terlebih dahulu peneliti dan siswa kelas II pada tahun 2014/2015 tepatnya Senin tanggal 7 September 2014, mengadakan prapenelitiantentang konsep benda berubah bentuk dan kegunaan benda di SDN 12 Nan Sabaris. Tujuannya adalah mengetahui metode yang cocok untuk materi benda berubah bentuk dan kegunaan benda, sehingga nantinya sudah punya konsep dalam proses pembelajaran IPA khususnya materi konsep bendabenda yang dikenal dan kegunaannya melalui pengamatan. Pada saat penelitian hasil yang diperoleh belum sesuai dengan kriteria ketuntasan minimal pembelajaran.

Selanjutnya peneliti melaksanakan penelitianberupa PTK dalam 2 siklus. Pada siklus I dilaksanakan 3 kali pertemuan, membahas tentang konsep ciri-ciri benda padat dan cair yang ada di lingkungan sekitar, masingmasing pertemuan memerlukan waktu 3 x 35 menit. Langkahpembelajarannyaadalah : Guru menyiapkan beberapa kartu yang berisi beberapa konsep atau topik yang cocok untuk sesi review, satu bagian kartu soal dan satu bagian kartu jawaban, Setiap siswa mendapat satu buah kartu, Tiap siswa memikirkan jawaban / soal dari kartu yang dipegang, Setiap siswa mencari pasangan yang mempunyai kartu yang cocok dengan kartunya (soal dan jawaban), Setiap siswa yang dapat mencocokkan kartunya sebelum batas waktu diberi poin, Setelah satu babak kartu dikocok lagi agar tiap siswa mendapat kartu yang berbeda dari sebelumnya. Demikian seterusnya.

Pembagianwaktunya 15 menitmotivasiawaldari guru danpembagiankelompok, 70 menitkegiatan di kelassertapresentasisederhanadarimasing-masingkelompok,maka 20menit kemudian di akhiridenganrangkumanoleh guru.

Setiapsiklusdiawalidenganpretesdanpadaakhirsiklusdiadakanpostes.Hasilpengamatanpadasiklus 
adalahsebagaiberikut,

yakni

(a)

guru

telahmemulaipelajarandenganmemberimotivasipadasiswadanmengakhiridenganmembuatrangkuman,

padasetiapkegiatan,

guru

telahberusahamendampingisiswa,

kegiatandiskusisiswamasihkurangaktifterutamakelompok $\quad 3$ danyang aktifkelompok 1 dan 2 (d) darihasilpostesadasebanyak 20 orang yang telahtuntasbelajar 7 orang dan 13orang yang belumtuntasbelajar. Hasilrefleksipadasiklus I adalah (a) keaktifansiswadalamkerjakelompokkurang,

siswabelummampumembuatkesimpulandenganbenar,(c)

mendorongsiswaberanimengajukandanmenjawabpertanyaan, (d) terdapat $35 \%$ siswatelahtuntasbelajar, dan guru siswabelumtuntasbelajar.

Dari refleksi tindakan pada siklus I disusun rencana tindakan siklus II sebagai berikut: yakni (1) guru merubah susunan kelompok dengan memasukkan siswa yang kurang berhasil menjadi 2 kelompok (kelompok I dan kelompok II), (2) memasukkan siswa yang belum tuntas ke dalam 2 kelompok tadi, (3) guru harus lebih memfokuskan perhatian kepada siswa yang belum tuntas, (4) guru menyarankan siswa bekerja lebih sistematis, dan (5) siswa diwajibkan membaca pelajaran minimal sehari sebelumnya.

Pada siklus II, dilaksanakan 3 kali pertemuan, masing-masing 3 x 35 menit. Konsep yang dibahas adalah konsep kegunaan benda meliputi: Pembagian waktu dan teknik pelaksanaannya secara umum sama dengan siklus I. Hasil pengamatan tindakan pada siklus II adalah sebagai berikut: yakni (a) guru melaksanakan proses pembelajaran dengan baik, (b) kerja kelompok siswa berjalan dengan baik, (c) siswa aktif berdiskusi dan mengajukan pertanyaan, (d) aktivitas kelompok yang menjadi fokus penelitian berjalan dengan baik dan aktif, (e) dari hasil postes terdapat $95 \%$ (9 orang yang telah tuntas belajar), sedangkan 1 orang belum tuntas belajar. Refleksi tindakan pada siklus II sebagai berikut: (a) kerja sama kelompok dan keaktifan berjalan dengan baik, (b) kelompok yang menjadi fokus penelitian mampu meningkatkan pemahaman konsepnya, (c) tingkat ketuntasan belajar secara klasikal mencapai $95 \%$ atau banyak 19 orang, berarti sudah berada di atas $80 \%$, dan (d) pelaksanaan siklus berikutnya tidak diperlukan lagi.

Dari kedua siklus tersebut diperoleh hasil secara berturut-turut yaitu (a) $65 \%$ pada siklus I, (b) $85 \%$ pada siklus II. Artinya ada peningkatan pemahaman konsep benda-benda yang dikenal dan kegunaannya melalui pengamatanyang dikuasai oleh siswa kelas II SDN 12 Nan Sabaris dalam proses pembelajaran IPA. Dengan demikian, hipotesis yang diajukan benda berubah bentuk dan kegunaan benda secara optimal dapat meningkatkan pemahaman konsep benda-benda yang dikenal dan kegunaannya melalui pengamatanpada siswa kelas II SDN 12 Nan Sabaris dapat diterima karena telah terbukti kebenarannya.

\section{PEMBAHASAN}

Menggunakan metodesmart game\&pembelajaran kooperatif tipe make a matchdalam mata pelajaran IPA dapat meningkatkan pemahaman konsep benda-benda yang dikenal dan kegunaannya melalui pengamatan pada siswa. Hal ini telah terbukti dari hasil pelaksanaan tindakan pada setiap siklus seperti diuraikan dalam bab IV yaitu pada hasil penelitian. Dari data tersebut, terdapat peningkatan pemahaman konsep benda-benda yang dikenal dan kegunaannya melalui pengamatan siswa yang sangat meyakinkan, artinya metode inkuiri sangat mendukung bila dimanfaatkan dalam proses pembelajaran karena dapat mempercepat pemahaman konsepbenda-benda yang dikenal dan kegunaannya melalui pengamatan pada kelas II SDN 12 Nan Sabaris.

Eggen dan Kauchak (1993) dalam Holil, mendefinisikan pembelajaran kooperatif (cooperative learning) sebagai sekumpulan stategi mengajar yang digunakan guru agar siswa saling membantu dalam mempelajari sesuatu. Oleh karena itu belajar kooperatif ini juga dinamakan "belajar teman sebaya"

Dalam penelitian ini, penulis menggunakan pembelajaran kooperatif tipe Make a Match. Tipe ini dikembangkan oleh Lorna Curran (1994). Salah satu keunggulan tipe ini adalah siswa mencari pasangan sambil belajar mengenai suatu konsep atau topik dalam suasana yang menyenangkan, siswa yang dapat mencocokkan kartunya sebelum batas waktu akan diberi poin.

Sementara menurut Slavin (1997), pembelajaran kooperatif berkenaan dengan berbagai macam metode pembelajaran yang perwujudannya siswa bekerja dalam kelompok-kelomok kecil dan saling membantu belajar materi akademis. Dalam kerjasama di kelas, partisipasi yang diharapkan dari siswa adalah saling membantu satu sama lain, berdiskusi dan berargumentasi satu sama lain, saling menilai pengetahuan dan perbedaan pemahaman satu sama lain. 
Penelitian ini juga berguna bagi guru, karena (1) guru dapat memperdalam pendekatan dan metode yang digunakan, (2) guru menjadi lebih profesional, karena meningkatnya pengetahuan dan pemahaman tentang penelitian tindakan kelas. Temuan ini didukung oleh Susilo (2000) menyatakan bahwa guru yang terampil melaksanakan penelitian tindakan kelas adalah guru yang selalu mau meningkatkan proses pembelajaran yang dikelolanya.

Implikasi penelitian ini bagi sekolah adalah sekolah memiliki guru yang profesional dan sekolah dapat menambah koleksi benda-benda yang berguna dalam proses pembelajaran. Tidak kalah penting artinya temuan ini bagi peneliti karena (1) dapat meningkatkan pengetahuan tentang penelitian tindakan kelas, (2) mengenal lebih dalam mata pelajaran IPA di SD, dan (3) dapat merintis kerja sama kemitraan dengan sekolah dan guru.

\section{PENUTUP}

Berdasarkan hasil penelitian dan pembahasan dapat disimpulkan sebagai berikut.

1. Menggunakan metodesmart game\&pembelajaran kooperatif tipe make a matchdalam proses pembelajaran dapat meningkatkan pemahaman konsep benda, bentuk dan kegunaan benda pada siswa. Hal ini dibuktikan dengan terjadinya peningkatan ketuntasan belajar siswa pada setiap siklus, yaitu $64,00 \%$ pada siklus I, 83,50\% pada siklus II.

2. Ketuntasan belajar pada siklus II yaitu $83,50 \%$ telah melampaui dari standar baku yaitu $75 \%$ sehingga pembelajaran sudah dianggap tuntas.

3. Kerja sama kelompok dalampermainansemakin meningkat pada setiap siklus. Keberhasilan ini ditunjukkan dengan aktifnya siswa dalam diskusi kelompok dan diskusi kelas, sehingga pembelajaran menjadi lebih bermakna bagi siswa.

4. Guru semakin kreatif dan profresional dan pengembangan proses pembelajaran di kelasnya.

Berdasarkan kesimpulan di atas, dapat disarankan sebagai berikut.

1. Pemerintah dalam membangun sekolah diharapkan supaya membuat halaman yang rindang dan kaya akan keanekaragaman tumbuhan, sehingga dapat digunakan dalam pembelajaran IPA, pelestarian lingkungan dan keindahandalam proses pembelajaran.

2. Kepada Depdiknas agar memberikan perhatian kepada guru-guru sehingga memahami dan melakukan penelitian tindakan kelas, sehingga dapat mengikuti masalah yang dihadapi dalam proses pembelajaran di sekolahnya.

3. Bagi kepala sekolah, disarankan agar memberikan peluang kepada gurunya untuk mengembangkan kreativitas dan profesionalismenya dalam pembelajaran, sehingga guru tidak hanya mentransfer ilmu pengetahuan tetapi mendorong siswa menemukan atau membuktikan teori melalui pengalaman langsung.

4. Bagi guru, diharapkan selalu menambahkan pengetahuan gagasan baru danmenggunakanmetode yang menyenangkandalam pembelajaran sehingga dapat meningkatkan gairah belajar siswa.

\section{DAFTAR PUSTAKA}

Arief, A. 1996. Menciptakan Situasi Belajar Mengajar yang Dinamis. Jurnal Chimera 1 (1) / 95:5 - 21

Arikunto, S. 1990. Lingkungan sebagai Sumber Belajar di Sekolah. Jakarta: Dirjen Dikti P2TK. Depdikbud.

Arikunto, S. 1999. Dasar-dasar Evaluasi Pendidikan. Jakarta: Bumi Aksara.

Darmodjo, H, \& Kaligis, J.R.E. 1992. Pendidikan IPA II. Jakarta: Depdikbud Dirjen Dikti P2TK.

Depdikbud. 1994. Kurikulum SD. Petunjuk Pelaksanaan Proses Belajar Mengajar. Jakarta: Depdikbud

Depdikbud. 1999. Penelitian Tindakan Kelas (Action Research). Jakarta: Depdikbud Dirjen Dikdasmen, Direktorat Pendidikan Menengah Umum

Rifai, M.A. 1992. Keanekaragaman Hayati dalam Kelas Sekolah. Surabaya: FRMIPA IKIP Surabaya.

Sardjono. 2000. Permasalahan Pendidikan di Sekolah dan Upaya Pemecahannya. Malang: Dirjen Dikti Depdiknas.

Sudjana, Nana. 1989. Penilaian Hasil Belajar Mengajar. Bandung: PT. Remaja Rosdakarya.

Slavin, Robert. 1986. Cooperative Learning Theory, Research and Practice (2nd). Boston: Allyn and Bacon.

Sukmadinata, N.S. 1988. Prinsip dan Landasan Perkembangan Kurikulum. Jakarta: Depdikbud Dirjen Dikti. P2LPTK. 
Sulasmi, E.S. 2000. Pengajaran Keanekaragamanan Tumbuhan di SMU, Permasalahan dan Pemecahannya. Malang: Depdiknas UM, FMIPA. Makalah, 23 Februari 2000.

Susilo, H. 2000. Pentingnya Penelitian Tindakan Kelas bagi Guru Masa Depan. Malang: Depdiknas Universitas Negeri Malang. Disajikan dalam Seminar Pemberdayaan Penalaran dengan Tema Penyiapan Generasi yang Berkualitas melalui Pengembangan Penalaran Siswa SD di SDN 2 Malang 15 April 2000.

Tim Peneliti Proyek PGSM. 1999. Penelitian Tindakan Kelas (Classroom Action Research). Jakarta: Depdikbud Dirjen Dikti P2GSM (Secondary School Teacher Development Project).

Yount, J.R \& Horton, P.B. 1992. Factor Influenching Enviromental Attitude: The Relationship Between Enviromental Attitude Defensibility and Cognitive Reasoning Level. Jurnal of Research in Science Teaching 29 (10) 1051-1077. 